\title{
A COMPARATIVE STUDY OF EPIDURAL VOLUME EXTENSION TECHNIQUE VERSUS SPINAL ANAESTHESIA USING HYPERBARIC BUPIVACAINE IN LOWER ABDOMINAL AND LOWER LIMB SURGERIES
}

\author{
Ivan Koshy1, Anita Mathew ${ }^{2}$, Farhat Singh ${ }^{3}$, Daljit Singh ${ }^{4}$
}

${ }^{1}$ Assistant Professor, Department of Anaesthesiology, Believer's Church Medical College, Thiruvalla, Kerala, India.

${ }^{2}$ Assistant Professor, Department of Anaesthesiology, Believer's Church Medical College, Thiruvalla, Kerala, India.

${ }^{3}$ Senior Consultant, Department of Anaesthesiology, St. Stephen's Hospital, Delhi, India.

${ }^{4}$ Senior Consultant, Department of Anaesthesiology, St. Stephen's Hospital, Delhi, India.

\section{ABSTRACT}

\section{BACKGROUND}

Epidural Volume Extension technique (EVE) via a combined spinal epidural technique is the enhancement of small dose intrathecal block by epidural saline boluses. ${ }^{1}$ Epidural volume extension of a small dose spinal block can provide adequate anaesthesia for lower abdominal and lower limb surgeries, while allowing faster motor recovery of the lower limbs. ${ }^{1}$

\section{MATERIALS AND METHODS}

Comparable groups of 30 each were given single shot intrathecal hyperbaric bupivacaine (Non-EVE Group) and other group was given epidural volume extension (EVE Group) by injecting $10 \mathrm{~mL} 0.9 \%$ saline via the epidural catheter. Groups were assigned by random number chart. Statistical analyses were performed using the SPSS version 9.0 for windows with Student's t-test, MannWhitney U-test and Chi-square test where appropriate. Statistical significance was assumed when $\mathrm{p}<0.05$.

\section{RESULTS}

The peak sensory block was T6 to T10 ( $\mathrm{P}<0.000)$. The mean time for sensory loss regression to T10 $(\mathrm{P}<0.002)$, reversal of Bromage score $(\mathrm{P}<0.002)$ and post-operative complications like shivering $(\mathrm{P}<0.000)$, nausea $(\mathrm{P}<0.000)$ and vomiting $(\mathrm{P}<0.038)$ were significant statistically.

\section{CONCLUSION}

We found that epidural volume extension technique could be used for surgeries above the umbilicus (T10) for a longer duration with faster motor recovery and less post-operative recovery stay and complications; however, small sample size is a limitation to this study.

\section{KEY WORDS}

Epidural Volume Extension Technique, Spinal Anaesthesia, Lower Limb and Abdominal Surgeries, Sensory and Motor Blockade.

HOW TO CITE THIS ARTICLE: Koshy I, Mathew A, Singh F, et al. A comparative study of epidural volume extension technique versus spinal anaesthesia using hyperbaric bupivacaine in lower abdominal and lower limb surgeries. J. Evolution Med. Dent. Sci. 2018;7(39):4258-4261, DOI: 10.14260/jemds/2018/950

\section{BACKGROUND}

Epidural Volume Extension technique (EVE) via a Combined Spinal Epidural technique (CSE) is the enhancement of small dose intrathecal block by epidural saline boluses. ${ }^{1}$ An epidural injection of physiological saline solution after spinal anaesthesia can produce a higher level of analgesia in comparison to spinal anaesthesia alone, because of volume effect. $^{2}$ The extradural injection of saline by causing compression of the subarachnoid space and spread of local anaesthetic and saline within may be another mechanism to explain this effect. It was postulated that epidural volume extension of a small dose spinal block could provide adequate anaesthesia for lower abdominal and lower limb surgeries while allowing faster motor recovery of the lower limbs. ${ }^{1}$

'Financial or Other Competing Interest': None.

Submission 14-08-2018, Peer Review 09-09-2018,

Acceptance 14-09-2018, Published 24-09-2018.

Corresponding Author:

Dr. Anita Mathew,

Assistant Professor

Department of Anaesthesiology,

Believer's Church Medical College

Thiruvalla, Kerala, India.

E-mail: dranitageomey@gmail.com

DOI: $10.14260 /$ jemds $/ 2018 / 950$
This is a comparative study of epidural volume extension technique and spinal anaesthesia using hyperbaric bupivacaine in lower abdominal and lower limb surgeries. We will be comparing its sensory blockade, motor blockade, postoperative analgesia and side effects of drugs or technique.

\section{MATERIALS AND METHODS}

A prospective, randomised, comparative study of two groups of 30 patients in each group with a total of 60 patients was performed after Hospital Ethics Committee approval and written informed consent. Patients were randomised (by computer generated random tables) to receive either singleshot spinal anaesthesia or a CSE technique with EVE. Place of study was Department of Anaesthesia of St. Stephen's Hospital, Delhi. Both groups underwent lower abdominal and lower limb surgeries. The sample size was taken for convenience during the study.

\section{Study Groups / Inclusion Criteria}

1. Patients undergoing elective lower abdominal and lower limb surgeries.

2. Patients of ASA I and ASA II.

3. Patients of age between 17 and 45 years.

4. Patients of height between $150 \mathrm{~cm}$ and $175 \mathrm{~cm}$.

5. Patients of weight between $45 \mathrm{~kg}$ and $85 \mathrm{~kg}$. 


\section{Exclusion Criteria}

1. Patients with systemic illness like hypertension, diabetes, thyroid, asthma or COPD.

2. Patients contraindicated to regional anaesthesia.

3. Pregnancy.

Informed consent was obtained after which a detailed history was taken with emphasis on history of any hypertensive disorder, diabetes mellitus, thyroid disorder, seizure disorder, COPD, any bleeding disorder, spinal defect or any underlying cardiac disease.

Patients were pre-medicated with tablet diazepam $10 \mathrm{mg}$ once in the night before the surgery and again two hours before the surgery. On arrival in the induction room, standard monitoring were applied with automated non-invasive blood pressure measurement, electrocardiogram monitoring and pulse oximetry. Baseline mean arterial blood pressure, heart rate and respiratory rate were recorded during the preanaesthetic check and in the post-operative stage also. All patients were preloaded with $500 \mathrm{~mL}$ of lactated Ringer's solution before induction of allocated regional anaesthetic technique. The regional technique was performed with the patient in sitting position at the L2-L3 and L3-L4 lumbar space using midline approach. Group 1 was single-shot intrathecal hyperbaric bupivacaine or the (Non-EVE Group) and Group 2 was the epidural extension volume technique group (EVE Group). For patients in (EVE Group) with the patient in sitting position, a 16-gauge Tuohy's needle was inserted at L2-L3 space using the technique of loss of resistance to air. An epidural catheter was inserted $3 \mathrm{~cm}$ into the extradural space and fixed. Following this $0.5 \%$ hyperbaric bupivacaine was injected at the L3-L4 space with a 25-guage Quincke's needle. For patients of height less than or equal to $163 \mathrm{~cm}, 1.6 \mathrm{~mL}$ and for height more than $163 \mathrm{~cm}, 1.8 \mathrm{~mL}$ of $0.5 \%$ hyperbaric bupivacaine was injected respectively. An additional 20 micrograms of fentanyl was added to the spinal drug in all patients. The sample size was taken for convenience during the study.

Five minutes after completion of intrathecal injection (taken as the point of removal of spinal needle), $10 \mathrm{~mL}$ of $0.9 \%$ saline was injected through the epidural catheter over 30 seconds. The completion of saline injection marked the completion of regional anaesthesia for patients in the EVE Group.

For the patients in Group 1, a single shot spinal anaesthesia with $0.5 \%$ hyperbaric bupivacaine $2.4 \mathrm{~mL}$ if the patient is less than or equal to $163 \mathrm{~cm}$ and $2.7 \mathrm{~mL}$ if the patient is more than $163 \mathrm{~cm}$ was given. An additional 20 micrograms of fentanyl was added to the spinal drug. The point at which the spinal needle was removed marked the completion of spinal anaesthesia. All procedures were performed under aseptic conditions. At the end of each regional technique, patients were positioned in supine position. Oxygen was administered by face mask. ECG, saturation, heart rate, respiratory rate and systolic blood pressure was monitored at 3 minutes interval for the first 15 mins. After that the vitals were checked every 10 minutes till the end of surgery. Similarly, the level of sensory block to loss of pain by pinprick with a 25-gauge hypodermic needle and modified Bromage motor score (Table 1) was checked at an interval of 3 minutes till there was no change.
Surgery was allowed to commence when the sensory block reached the $5^{\text {th }}$ thoracic dermatome (T5) or 10 minutes had elapsed.

At the point of surgical incision, the intraoperative visual analog pain score was assessed on a 101-point scale and repeated intraoperatively whenever pain or discomfort was expressed. If visual analog pain score was more than 30 , analgesia was supplemented with $3 \mathrm{~mL}$ of $2 \%$ lignocaine with adrenaline (Group 2) or intravenous adjuncts such as fentanyl 25 micrograms and ketorolac $30 \mathrm{mg}$ (for both groups). If these failed to reduce pain to less than 30 , general anaesthesia was offered to the patient.

At the recovery room, all patients were monitored by trained nurses. The time intervals for sensory recovery to the $10^{\text {th }}$ dermatome (T10) and the motor recovery to modified Bromage 0 were ascertained by testing for sensory loss to pinprick and getting the patient to perform straight leg test and knee bend respectively every 15 minutes. Bromage 0 is no motor block, 1 is absent hip flexion but able to move knees and ankles, 2 is able to move only the ankles and 3 is no movement at any joint.

Statistical analyses were performed using the SPSS version 9.0 for windows with Student's t-test, Mann-Whitney U-test and Chi-square test where appropriate. Statistical significance was assumed when $\mathrm{p}<0.05$.

\section{RESULTS}

Table 2 shows distribution of Bromage score at the beginning of the surgery. At the start of surgery, all patients (100.0\%) in Group I had Bromage three score and only six patients (20.0\%) in Group II had Bromage three score.

The p-value obtained 0.000 was significant statistically. Table 3 shows the mean time interval to the effect of regression of sensory loss, time to Bromage 0 and the time for first request of post-op analgesia. The mean time for sensory loss regression to T10 level was 100.67 and 116.0 mins in Group I and Group II respectively (Table 4).

This was found to be statistically significant with a p-value of $<0.002$. In our study, Group I patients took longer time (202.50 mins) to go back to Bromage score zero as compared to Group II (103.67 mins). The comparative p-value $<0.002$ was significant statistically.

Group I patients requested for post-operative analgesia after a longer time (234.0 mins) as compared to Group II patients (161.33 mins). P value calculated was 0.000 , which was very significant statistically.

In our study, Group I patients had a larger peak sensory block with a minimum level of $\mathrm{T}_{10}$ to maximum $\mathrm{T}_{6}$. In Group II, the minimum sensory block was till level $\mathrm{T}_{6}$ and maximum to $\mathrm{T}_{4}$ (Table 4). The difference was found to be statistically significant with a p-value $<0.000$.

In our study, shivering was encountered most commonly in Group I (56.7\%). Only one patient (3.3\%) complained of shivering during surgery in Group II (Table 5a). This difference was statistically significant with a p-value $<0.000$.

There were eleven patients (36.7\%) in Group I who complained of nausea during the surgery, whereas none of the patients $(.0 \%)$ in Group II had nausea (Table $5 \mathrm{~b})$. The p-value obtained was statistically significant. 
Four patients had vomiting in Group I and none in Group II (Table 5c). The difference was found to be statistically significant with a p-value $<0.038$.

\begin{tabular}{|c|c|}
\hline Bromage 0 & No motor block \\
\hline Bromage 1 & $\begin{array}{c}\text { Absent hip flexion, but able to move } \\
\text { knees and ankles }\end{array}$ \\
\hline Bromage 2 & $\begin{array}{c}\text { Absent hip and knee flexion, but able to } \\
\text { move only ankles }\end{array}$ \\
\hline Bromage 3 & No movement in any of the three joints \\
\hline \multicolumn{2}{|c|}{ Table 1. Bromage Score } \\
\hline
\end{tabular}

\begin{tabular}{|c|c|c|c|c|c|c|c|}
\hline \multirow{2}{*}{\multicolumn{3}{|c|}{$\begin{array}{l}\text { Bromage Score } \\
\text { at 0 Min }\end{array}$}} & \multicolumn{4}{|c|}{0 Min } & \multirow{3}{*}{$\begin{array}{c}\text { Total } \\
30\end{array}$} \\
\hline & & & \multirow{2}{*}{$\begin{array}{l}\mathbf{0} \\
0 \\
\end{array}$} & \multirow{2}{*}{$\frac{1}{0}$} & \multirow[t]{2}{*}{2} & \multirow{2}{*}{$\begin{array}{r}3 \\
30 \\
\end{array}$} & \\
\hline \multirow{4}{*}{ Group } & \multirow[b]{2}{*}{$\begin{array}{l}\text { Group } \\
\text { I }\end{array}$} & $\mathrm{N}=30$ & & & & & \\
\hline & & $\begin{array}{l}\text { \% within } \\
\text { Group }\end{array}$ & $.0 \%$ & $.0 \%$ & $.0 \%$ & $100.0 \%$ & $100.0 \%$ \\
\hline & \multirow[b]{2}{*}{ Group } & $\mathrm{N}=30$ & 0 & 0 & 24 & 6 & 30 \\
\hline & & $\begin{array}{l}\text { \% within } \\
\text { Group }\end{array}$ & $.0 \%$ & $.0 \%$ & $80.0 \%$ & $20.0 \%$ & $100.0 \%$ \\
\hline \multirow{2}{*}{\multicolumn{2}{|c|}{ Total }} & $\mathrm{N}=60$ & 0 & 0 & 24 & 36 & 60 \\
\hline & & $\begin{array}{l}\text { \% within } \\
\text { Group }\end{array}$ & $.0 \%$ & $.0 \%$ & $40.0 \%$ & $60.0 \%$ & $100.0 \%$ \\
\hline \multicolumn{8}{|c|}{$\begin{array}{c}\text { Table 2. Distributions of Bromage Score at } \\
\text { Beginning of Surgery }\end{array}$} \\
\hline
\end{tabular}

\begin{tabular}{|c|l|l|l|c|c|}
\hline & Group & $\mathbf{N}$ & $\begin{array}{l}\text { Mean } \\
\text { (Min) }\end{array}$ & $\begin{array}{c}\text { Std. } \\
\text { Deviation }\end{array}$ & $\begin{array}{c}\text { P- } \\
\text { value }\end{array}$ \\
\hline $\begin{array}{c}\text { Time to sensory } \\
\text { level regression } \\
\text { to T10 }\end{array}$ & Group I & 30 & 100.67 & 21.764 & 0.002 \\
\cline { 2 - 6 } & Group II & 30 & 116.00 & 12.959 & \\
\hline $\begin{array}{c}\text { Time to } \\
\text { Bromage score } \\
0\end{array}$ & Group I & 30 & 202.50 & 21.566 & 0.000 \\
\cline { 2 - 6 } & Group II & 30 & 103.67 & 14.320 & \\
\hline $\begin{array}{c}\text { Time to first } \\
\text { request of post- } \\
\text { op analgesia }\end{array}$ & Group I & 30 & 234.00 & 24.927 & 0.000 \\
\cline { 2 - 6 } & Group II & 30 & 161.33 & 18.096 & \\
\hline
\end{tabular}

Table 3. Distribution of Mean Time Interval to effect of Regression of Sensory Loss, Time to Bromage 0 and Time to First Request of Post-Op Analgesia

\begin{tabular}{|c|c|c|c|c|}
\hline & $\begin{array}{c}\text { Minimum } \\
\text { Peak Sensory } \\
\text { Block (T) }\end{array}$ & $\begin{array}{c}\text { Maximum Peak } \\
\text { Sensory Block } \\
\text { (T) }\end{array}$ & Mean & $\begin{array}{c}\text { Std. } \\
\text { Deviation }\end{array}$ \\
\hline Group 1 & 10 & 6 & 7.40 & 0.932 \\
\hline Group 2 & 6 & 4 & 4.97 & 0.490 \\
\hline Table 4. Distribution showing difference in Peak Sensory \\
Block between the Two Groups \\
\hline
\end{tabular}

( $\mathrm{T}=$ Thoracic Dermatome)

Table 5A. Distribution of Patients according to Complications during of surgery and post-operative

\begin{tabular}{|c|c|c|c|c|c|}
\hline & \multicolumn{2}{|c|}{ Shivering } & \multirow{2}{*}{ Total } \\
\hline & & & No & Yes & \\
\hline \multirow{4}{*}{ Group } & \multirow{2}{*}{ Group I } & $\mathrm{N}=30$ & 13 & 17 & 30 \\
\hline & & $\%$ within Group & $43.3 \%$ & $56.7 \%$ & $100.0 \%$ \\
\hline & \multirow{2}{*}{ Group II } & $\mathrm{N}=30$ & 29 & 1 & 30 \\
\hline & & $\%$ within Group & $96.7 \%$ & $3.3 \%$ & $100.0 \%$ \\
\hline \multirow{2}{*}{\multicolumn{2}{|c|}{ Total }} & $\mathrm{N}=60$ & 42 & 18 & 60 \\
\hline & & $\%$ within Group & $70.0 \%$ & $30.0 \%$ & $100.0 \%$ \\
\hline \multicolumn{6}{|c|}{ Table 5A. Shivering } \\
\hline
\end{tabular}

\begin{tabular}{|c|c|c|c|c|c|}
\hline & \multicolumn{2}{|c|}{ Nausea } & \multirow{2}{*}{ Total } \\
\hline & & & No & Yes & \\
\hline \multirow{4}{*}{ Group } & \multirow{2}{*}{$\begin{array}{c}\text { Group } \\
\text { I }\end{array}$} & $\mathrm{N}=30$ & 19 & 11 & 30 \\
\hline & & $\begin{array}{l}\text { \% within } \\
\text { Group }\end{array}$ & $63.3 \%$ & $36.7 \%$ & $100.0 \%$ \\
\hline & \multirow[b]{2}{*}{$\begin{array}{c}\text { Group } \\
\text { II }\end{array}$} & $\mathrm{N}=30$ & 30 & 0 & 30 \\
\hline & & $\begin{array}{l}\text { \% within } \\
\text { Group }\end{array}$ & $100.0 \%$ & $.0 \%$ & $100.0 \%$ \\
\hline \multirow{2}{*}{\multicolumn{2}{|c|}{ Total }} & $\mathrm{N}=60$ & 49 & 11 & 60 \\
\hline & & $\begin{array}{c}\% \text { within } \\
\text { Group }\end{array}$ & $81.7 \%$ & $18.3 \%$ & $100.0 \%$ \\
\hline
\end{tabular}

\begin{tabular}{|c|c|c|c|c|c|}
\hline & \multicolumn{2}{|c|}{ Vomiting } & \multirow[t]{2}{*}{ Total } \\
\hline & & & No & Yes & \\
\hline \multirow[t]{4}{*}{ Group } & \multirow[t]{2}{*}{ Group I } & $\mathrm{N}=30$ & 26 & 4 & 30 \\
\hline & & $\begin{array}{l}\text { \% within } \\
\text { Group }\end{array}$ & $86.7 \%$ & $13.3 \%$ & $100.0 \%$ \\
\hline & \multirow[t]{2}{*}{ Group II } & $\mathrm{N}=30$ & 30 & 0 & 30 \\
\hline & & $\begin{array}{c}\text { \% within } \\
\text { Group }\end{array}$ & $100.0 \%$ & $.0 \%$ & $100.0 \%$ \\
\hline \multirow{2}{*}{\multicolumn{2}{|c|}{ Total }} & $\mathrm{N}=60$ & 56 & 4 & 60 \\
\hline & & $\begin{array}{c}\text { \% within } \\
\text { Group }\end{array}$ & $93.3 \%$ & $6.7 \%$ & $100.0 \%$ \\
\hline \multicolumn{6}{|c|}{ Table 5C. Vomiting } \\
\hline
\end{tabular}

\section{DISCUSSION}

The most frequently performed surgery in this study was hernioplasty twenty-one (35\%) followed by hip release surgeries seven $(11.7 \%)$ and Wilson release surgeries six (10\%). Ten patients (33.3\%) in Group I and eleven patients (36.7\%) in Group II underwent hernioplasty. In the other group one patient each underwent DHS, osteotomy, screw removal and stripping in Group I and one patient underwent femur nailing in Group 2.

In this study, Group I patients took longer time (202.50 mins) to go back to Bromage score zero as compared to Group II (103.67 mins). The comparative p-value $<0.002$ was significant statistically. In study by Eileen Lew, Seow-Yeo and Easow Thomas et al $^{1}$ showed similar faster motor recovery profile while using epidural volume extension technique. The same findings were comparable in an Indian study by Tyagi A, Kumar A, Sethi AK, Mohta M et al, ${ }^{2}$ which helped the patients in reducing or bypassing post-anaesthetic care unit. In this study, epidural volume extension technique showed a faster recovery of motor block compared to spinal group. This led to lesser stay in post-operative recovery room and thereby the total cost of stay in the hospital was cut short. ${ }^{3}$

In this study, Group I patients had a higher peak sensory block with a minimum level of $\mathrm{T}_{10}$ to maximum $\mathrm{T}_{6}$. In Group II, the minimum sensory block was till level $\mathrm{T}_{6}$ and maximum to $\mathrm{T}_{4}$. The difference was found to be statistically significant with a p-value $<0.000$. The mean time for sensory loss regression to T10 level was 100.67 and 116.0 mins in Group I and Group II respectively. This was found to be statistically significant with a p-value of $<0.002$. Stienstra et $\mathrm{al}^{4}$ demonstrated an increase in maximal sensory block height with epidural bupivacaine $0.5 \%$ bupivacaine or saline $0.9 \%$. In a study by Takiguchi et al, 5 sensory block level reached a maximum of T5 and a minimum of T9 in the epidural volume extension group as against a maximum of T11 and minimum of L2 in the spinal group. This goes to show that a higher level of block is being 
achieved in this study as well as other studies where higher abdominal surgeries can be performed without compromising on the haemodynamics.

Group I patients requested for post-operative analgesia after a longer time (234.0 mins) as compared to Group II patients (161.33 mins). P-value calculated was 0.000 , which was very significant statistically. In a similar study by Eileen et $\mathrm{al}^{1}$ the time for request to post-operative analgesia for spinal and epidural volume extension group was a mean of 688 and 563 minutes respectively, which was statistically insignificant. But in this study, it was significant showing that spinal group enjoyed a longer time of analgesia as compared to epidural volume extension group, which is the only disadvantage of epidural volume extension technique. This was overcome by post-operative analgesia through the already placed epidural catheter. In other study by Blumgart et al, ${ }^{6}$ the time to first request to post-operative analgesia was more in the spinal group as compared to epidural group.

In Group II post-operative shivering was found in only one patient and none of the patients complained of any nausea or vomiting, whereas the patients in the spinal group did experience post-operative shivering, nausea and vomiting. This was found to be statistically significant. Hence, patients who underwent epidural volume extension technique were found to have lesser post-operative complications.

\section{CONCLUSION}

From this study, it is seen that epidural volume extension technique is better than intrathecal technique, because it offered faster motor recovery, higher peak sensory level and less complications. Hence, it is more economical, has a shorter recovery stay, better patient satisfaction and safer in patients who are haemodynamically unstable. The limitation of the epidural volume extension technique is that the postoperative analgesia time is less than the intrathecal group. The other limitation of this study is the small sample size used.

\section{ACKNOWLEDGEMENT}

I thank Dr. Sudhir Joseph the Director of St. Stephen's Hospital, Delhi and Dr. Grace Cherian the Head of Department of St. Stephen's Hospital, Delhi for allowing me to conduct my study. A special thanks to the operation theatre staff and anaesthesia technicians. I also wish to thank Dr. George Thomas, Associate Professor in the Department of ENT, Believer's Church Medical College, Thiruvalla, Kerala for compilation and formatting of the article.

\section{REFERENCES}

[1] Lew E, Yeo SW, Thomas E. Combined spinal-epidural anesthesia using epidural volume extension leads to faster motor recovery after elective cesarean delivery: a prospective, randomized, double-blind study. Anesth Analog 2004;98(3):810-4.

[2] Tyagi A, Kumar A, Sethi AK, et al. Epidural volume extension and intrathecal dose requirement: plain versus hyperbaric bupivacaine. Anaesth Analog 2008;107(1):333-8.

[3] Rawal N, Schollin J, Wesstrom G. Epidural versus combined spinal epidural block for caesarean section. Acta Anaesthesiology Scand 1988;32(1):61-6.

[4] Stienstra R, Dahan A, Alhadi BZ, et al. Mechanism of action of an epidural top-up in combined spinal-epidural anaesthesia. Anesth Analg 1996;83(2):382-6.

[5] Takiguchi T, Okano T, Egawa H, et al. The effect of epidural saline injection on analgesic level during combined spinal and epidural anesthesia assessed clinically and myelographically. Anesth Analog 1997;85(5):1097-100.

[6] Blumgart CH, Ryall D, Dennison B, et al. Mechanism of extension of spinal anaesthesia by extradural injection of local anesthetic. Br J Anesth 1992;69(5):457-60. 